\title{
Impact of Overlapping Functional Gastrointestinal Disorders on the Quality of Life in Patients With Gastroesophageal Reflux Disease
}

\author{
Shou-Wu Lee ${ }^{1,2}$ and Chi-Sen Chang ${ }^{1,2 *}$ \\ ${ }^{I}$ Division of Gastroenterology, Department of Internal Medicine, Taichung Veterans General Hospital, Taichung; Taiwan and ${ }^{2}$ Department of \\ Internal Medicine, Chung Shan Medical University, Taichung, Taiwan
}

\begin{abstract}
Gastroesophageal reflux disease (GERD) and functional gastrointestinal disorders (FGIDs), including irritable bowel syndrome and functional dyspepsia, are common afflictions within the general population. Both conditions have a considerable impact on the daily health related quality of life (HRQoL) of affected individuals. Risk factors surrounding any impaired HRQoL in patients with GERD involve those of younger age, obesity, an increase in reflux symptom frequency, and overlapping FGIDs. The risk factors for subjects experiencing an overlap in FGIDs and GERD involve those who are female, younger age, cigarette smoking, non-erosive reflux disease, more GERD symptoms, and psychological performances including anxiety, somatization, and more frequent healthcareseeking behavior. The overlap of GERD and FGIDs is associated with a worsening of both physical and mental health, an increase in bothersome symptoms, impaired functional capacity, and a higher likelihood of consulting a physician. Acid secretion suppressors could offer therapeutic efficacy to some patients experiencing overlapping GERD and FGIDs.
\end{abstract}

(J Neurogastroenterol Motil 2021;27:176-184)

Key Words

Dyspepsia; Female; Gastroesophageal reflux; Quality of life

\section{Introduction}

Gastroesophageal reflux disease (GERD) and functional gastrointestinal disorders (FGIDs) are very common within the general population, and both conditions have a considerable impact on the daily lives of affected individuals. ${ }^{1-4}$

According to previous studies, the risk factors in patients with GERD include older age, ${ }^{5,6}$ obesity, ${ }^{7,8}$ hiatus hernia, ${ }^{9}$ and an unhealthy lifestyle, involving alcohol intake and cigarette smoking.
The symptoms of GERD affect many aspects of a patient's life, including sleep disruption, lower attention concentration levels, and limitations in physical activity; as well as impairing the psychosocial aspects of a patient's well-being, including the enjoying of social gatherings, intimacy, and sex. Health related quality of life (HRQoL) is lower in individuals with GERD than in the general population, and is comparable to that in individuals with other chronic diseases, such as diabetes, arthritis, and chronic heart failure. $^{1}$

FGIDs, such as irritable bowel syndrome (IBS), functional

Received: January 5, 2019 Revised: May 4, 2020 Accepted: January 2, 2021

(.) This is an Open Access article distributed under the terms of the Creative Commons Attribution Non-Commercial License (http://creativecommons. org/licenses/by-nc/4.0) which permits unrestricted non-commercial use, distribution, and reproduction in any medium, provided the original work is properly cited.

*Correspondence: Chi-Sen Chang, MD, PhD

Division of Gastroenterology, Department of Internal Medicine, Taichung Veterans General Hospital, No. 1650, Taiwan Boulevard Section 4, Taichung, 40705 Taiwan

Tel: +886-4-23592525 (ext. 3301), Fax: +886-4-23595046, E-mail: changcs1957@gmail.com 
dyspepsia (FD), and chronic constipation, all pose an extensive healthcare burden and negatively affect quality of life $(\mathrm{QoL}){ }^{4} \mathrm{~Pa}$ tients with GERD also suffer more commonly from FGIDs.

The aim of this review is to investigate the impact of $\mathrm{HRQoL}$ of the subjects experiencing an overlap of GERD and FGIDs.

\section{Definition of Gastroesophageal Reflux Dis- ease and Functional Gastrointestinal Disor- ders}

According to the Montreal definition, GERD is a condition which develops when the reflux of stomach contents causes troublesome symptoms and/or complications. ${ }^{10}$ In addition, based on the Genval guidelines, a negative impact on the $\mathrm{QoL}$ is a criterion for reflux disease in patients with frequent heartburn. ${ }^{11}$

Clinically, individuals with GERD may experience its classic syndromes, including heartburn and regurgitation; along with nonclassic syndromes, including chest pain, globus sensation, chronic cough, and hoarseness. Heartburn is usually characterized by the involvement of a burning substernal or epigastric discomfort which radiates towards the mouth. Here, regurgitation refers to the reflux of food or bitter-tasting gastric contents emanating from the stomach into the mouth.

GERD is further classified based on the appearance of the esophageal mucosa seen from an upper endoscopy into erosive esophagitis and non-erosive reflux disease (NERD).

Over the years, FGIDs have been diagnosed and classified according to the Rome criteria. Within the Rome II criteria, FD is defined as pain or discomfort centered in the upper abdomen, with no emphasis given to meal-related symptoms. ${ }^{12}$ As defined by the Rome III criteria, FD is a disorder including 1 or more of the following: bothersome postprandial fullness, early satiation, epigastric pain, epigastric burning, and no evidence of any structural disease. The criteria fulfilled for the last 3 months with symptom onset at least 6 months prior to diagnosis. FD can be further divided into postprandial distress syndrome, characterized by meal-induced dyspeptic symptoms, and epigastric pain syndrome, which refers to epigastric pain or epigastric burning that does not occur exclusively postprandially, according to symptom presentation. ${ }^{13}$ IBS manifests itself as recurrent abdominal pain or discomfort at least 3 days per month in the last 3 months, with at least 2 of the following characteristics: (1) relief through defecation, (2) onset associated with a change in the frequency of stool, and (3) onset associated with a change in the form of stool. The type of IBS is further divided into diarrhea, constipation, and a combination of the two. ${ }^{13}$
IBS has traditionally been subcategorized into 4 subtypes based on predominant stool pattern: constipation, diarrhea, mixed, or unsubtyped. $^{14}$

The updated Rome IV diagnostic criteria categorize the FGIDs of gut-brain interaction, and define the symptom based diagnostic criteria for each category. ${ }^{15}$ The classifications of FGIDs according to the Rome IV criteria include esophageal disorders (globus, functional chest pain, functional heartburn, functional dysphagia, and reflux hypersensitivity), gastroduodenal disorders (FD, belching disorders, nausea/vomiting disorders, and rumination syndrome), along with bowel disorders (including IBS, functional abdominal bloating/distension, functional constipation, and functional diarrhea)

According to the current consensus, FGIDs are considered to be a group of disorders classified by gastrointestinal (GI) symptoms relate to any combination of the following: motility disturbance, visceral hypersensitivity, altered mucosal and immune function, altered gut microbiota, and altered central nervous system processing.

\section{Risk Factors of Impaired Health Related Quality of Life in the Individuals With Gas- troesophageal Reflux Disease}

GERD is a chronic disease reportedly to be more severe and possessing a higher incidence of severe complications in older versus younger patients. ${ }^{16}$ On the contrary, elderly patients present themselves less frequently with the typical symptoms of heartburn, acid regurgitation, and pain. ${ }^{17}$ Therefore, the younger GERD patients are found to have a significant degree of $\mathrm{QoL}$ impairment than the elderly, ${ }^{2,6,18}$

As for the impact gender has on HRQoL in GERD, a previous study found that women had poorer general scores than men. ${ }^{19}$ However, this trend may be due to a heightened sensitivity and symptom perception of female patients diagnosed with NERD.

One cross-sectional study in the United States enrolled 1524 subjects who were reported to be obese (defined as a body mass index over $30 \mathrm{~kg} / \mathrm{m}^{2}$ ), and were associated with experiencing frequent reflux symptoms (OR, 2.8; CI, 1.7 to 4.5$).{ }^{20}$ Additionally, the condition of being overweight or obese has been associated with a deterioration in $\mathrm{HRQoL}$, and the risk of suffering from any longstanding illness is associated with an increased body mass index. ${ }^{21}$ For these obese patients, women perceived themselves having markedly more psychosocial problems due to their obesity than did men. ${ }^{22}$

NERD accounts for $60 \%$ of all chronic heartburn cases in a community due to the heterogeneous form of its pathophysiological 
mechanisms. ${ }^{23}$ A meta-analysis of 5 trials incorporating a total of 11945 GERD subjects found no correlation between the severity of esophagitis and its symptoms. ${ }^{24}$ In addition, patients with erosive esophagitis and those with NERD had similar general HRQoL scores according to previous investigations. ${ }^{3,19,24-26}$

One study was conducted within Sweden's general population which assessed the impact of the severity and frequency of GERD symptoms. Those results showed that even symptoms rated as mild are associated with a clinically meaningful reduction in wellbeing. ${ }^{27}$ Other studies have documented an increasing symptom frequency of heartburn which has led to significant decreases in wellbeing. ${ }^{28,29}$ One past study enrolling 136 Swedish subjects showed that patients with GERD symptoms reported a $23 \%$ reduced productivity rate while at work, and a $30 \%$ reduced productivity rate while doing regular daily activities. ${ }^{30}$ In addition, time absent from work for health reasons and reduction in productivity at work both became significantly more pronounced with increasing severity of GERD symptoms. ${ }^{31}$

Another study containing 3000 Swedish adults reported that weekly reflux symptoms were associated with meaningfully impaired HRQoL in the physical dimensions of short-form (SF)-36, while daily symptoms had meaningfully impaired HRQoL in both physical and psychosocial dimensions. ${ }^{2}$

A systematic review of 19 studies, including a total of 55834 participants with reflux symptoms, disclosed that both the mean physical health and mental health scores were 1.1-fold lower in the groups with "disruptive," which mean severe and frequent GERD, than in those with "non-disruptive" GERD. Additionally, the groups with more severe reflux symptoms had lower physical health scores than those with less severe symptoms. ${ }^{32}$

One large European multicenter observational study noted that more than half of GERD patients experienced sleep disturbance, and that persistent regurgitation was associated with more hours of missed work. ${ }^{33}$ Sleep disturbance and associated daytime sleepiness, a decrease in mealtime enjoyment, and increased medication costs that may also contribute to the burden of disease. ${ }^{19}$

Overlapping FGIDs have a significant impact on the HRQoL of subjects with GERD, and the details regarding that will be discussed later.

\section{The Prevalence and Risk Factors for Indi- viduals With Overlapping Functional Gastro- intestinal Disorders and Gastroesophageal Reflux Disease}

GERD and FGIDs are very common within the general population. Since GERD and FGIDs are both prevalent, coexistence may often be observed.

Past epidemiological studies which investigated the prevalence of dyspeptic and esophageal symptoms have reported a higher prevalence of dyspeptic symptoms in patients with GERD, suggesting that the degree of overlap is greater than could be predicted through chance alone. ${ }^{34}$ The reason for this may be due to the 2 diseases sharing pathophysiological mechanisms, including visceral hypersensitivity and altered GI motility.

A nationwide study of 100000 individuals within the Danish population implemented a web-based questionnaire survey. Respondents with GERD-FD, GERD-IBS, or GERD-FD-IBS complexes numbered 881 (1.9\%), 790 (1.7\%), and 770 (1.6\%), respectively. ${ }^{35}$ One study in France reported FGIDs overlap to be as high as $72.0 \%$ in all 3318 GERD patients using the Rome II diagnostic criteria, with more GERD symptoms found to be associated with an increased prevalence of FGIDs. ${ }^{36}$ Another study involving 1001 Swedish subjects from the Kalixanda study found FD in 157 (16.0\%) patients when applying the Rome III criteria. Among these cases, the overlap of GERD-FD and GERD-FDIBS was $39(3.9 \%)$ and $58(5.8 \%)$ respectively. ${ }^{37}$

One cross-sectional study which enrolled 63 GERD and 48 overlapping GERD-FD Chinese patients in Taiwan found a significantly younger age $(40.54 \pm 15.75$ years vs $51.43 \pm 16.64$ years, $P=0.001)$, and significantly higher number of the female gender $(70.8 \%$ vs $34.9 \%, P=0.001)$ in the GERD-FD group compared to those in the GERD only group. ${ }^{38}$

In a recent review, the overlap of GERD with IBS spanned in values ranging from $3.0-79.0 \%$, which may be due to different diagnostic criteria of IBS, such as the Manning, Rome I, Rome II, or Rome III criteria. ${ }^{39}$ Another meta-analysis study involving 13 reports found the proportion of IBS with GERD-type symptoms in IBS individuals was as high as $42.0 \%$. The overall OR of GERD-type symptoms in individuals with IBS was 4-fold to that of individuals without IBS. ${ }^{40}$ The strength of positive association between GERD and IBS varied from 3.53 (CI, 2.05 to 6.10) when the Rome I criteria for IBS were used, to 9.59 (CI, 7.14 to 12.87) with the Rome III criteria. ${ }^{40}$ 


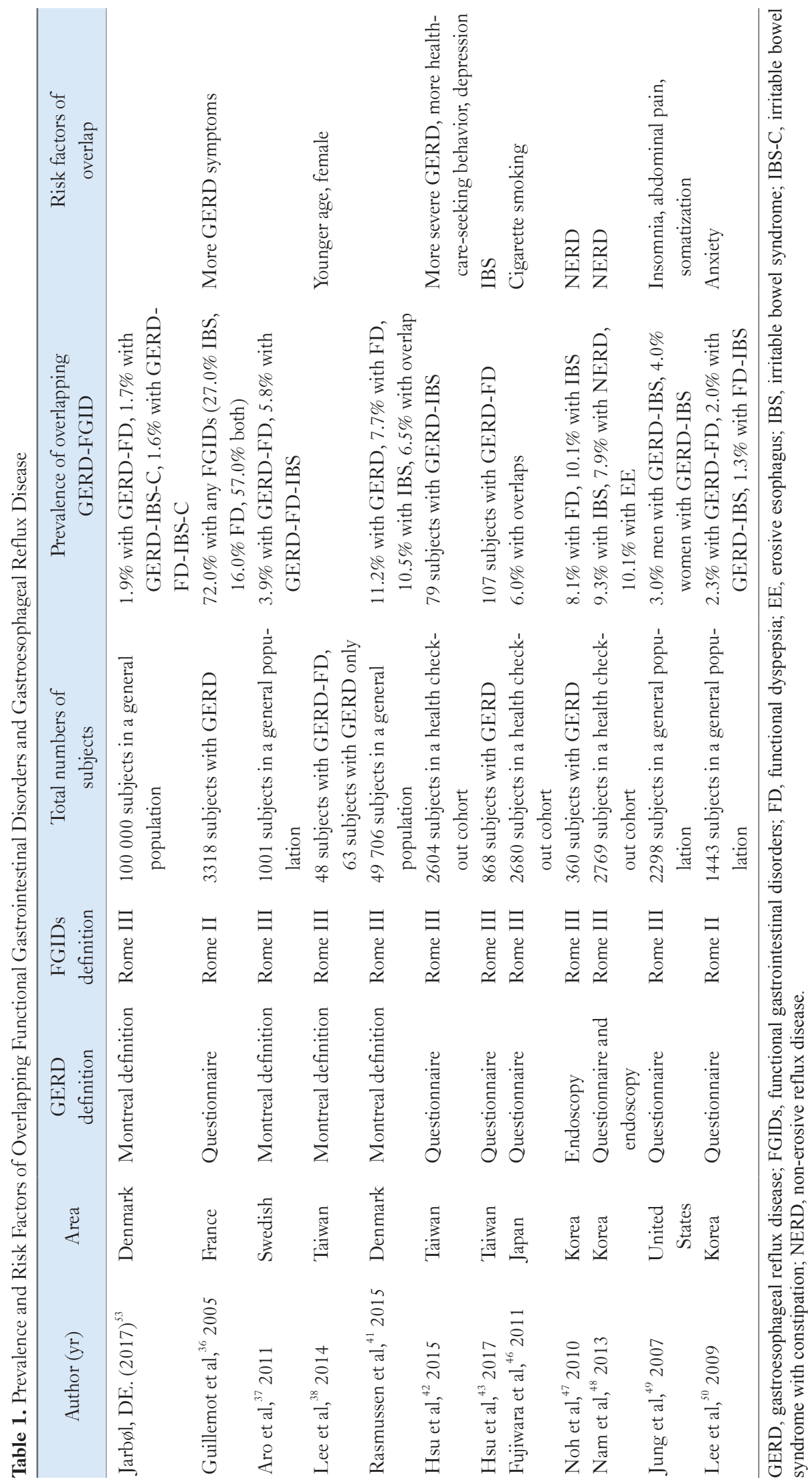


One nationwide study in Denmark enrolling 49706 randomly selected individuals who underwent a web-based questionnaire survey, showed the prevalence of GERD, FD, and IBS (Rome III criteria) to be $11.2 \%, 7.7 \%$, and $10.5 \%$, respectively. Notably, the overlap between these conditions was $6.5 \%$. $^{41}$

In a case-control study including 2604 healthy check-up subjects from Taiwan, the prevalence of IBS (Rome III criteria) was at least $10.0 \%$ in patients with GERD and $5.5 \%$ in those without. Those experiencing an overlap of the 2 conditions had more severe GERD, more frequent healthcare-seeking behavior, and higher depression scores. ${ }^{42}$ In a further subgroup analysis of 868 GERD cohort involving 107 cases with overlap GERD and dyspepsia, overlapping subjects were more often associated with IBS, as compared to subjects with GERD alone (OR, 3.54; CI, 1.92 to 6.52). ${ }^{43}$

The majority of FGIDs are more prevalent in women than in men, ${ }^{44}$ and the pathogenesis may be associated with delayed gastric emptying in the female sex. ${ }^{45}$ Another study reported that cigarette smoking was significantly associated with overlaps among GERD, FD, and IBS in Japanese adults. ${ }^{46}$ Furthermore, NERD has been reported to be more frequently overlapped with both $\mathrm{FD}$ and IBS. $^{47,48}$

Emotional factors, such as anxiety and higher somatization, are common in the overlaps between GERD and FGIDs. ${ }^{49,50}$

Table 1 summarizes the studies demonstrating the prevalence and risk factors of overlapping GERD and FGIDs.

\section{Overlap Functional Gastrointestinal Disor- ders on the Quality of Life in Individuals With Gastroesophageal Reflux Disease}

A study which enrolled 1001 adult Swedish subjects revealed that the overlap of GERD with FD had a statistically significant impact on SF-36 scores for bodily pain compared with FD only (mean scores 63.1 vs $72.4, P=0.020)^{37}$

A previous study involving 111 ethnic Chinese individuals in Taiwan found that patients in the GERD-FD group exhibited the lowest QoL scores, with respect to both physical (58.13 \pm 15.31 vs $71.27 \pm 15.98, P=0.001)$ and mental health $(50.46 \pm 15.51$ vs $68.33 \pm 15.87, P=0.001)$, when compared to the GERD group without FD. ${ }^{38}$

In another case-control study from Taiwan, the patients with overlap GERD and IBS reported poorer sleep quality (OR, 1.11; $\mathrm{CI}, 1.01$ to 1.21), and greater levels of depression (OR, 1.06; CI, 1.02 to 1.10 ), than those with GERD alone. ${ }^{42,50}$

One cross-sectional study of 2680 Japanese workers noted that overlaps of GERD, FD, and IBS significantly worsened HRQoL in most domains, and the overlap of GERD was associated with a significantly worsening physical health score than FD alone and IBS alone. ${ }^{51}$

One study which enrolled 263 patients in the Netherlands found overlapping GERD + FD, GERD + IBS, and GERD + FD + IBS having significantly lower scores on 6, 8, and 7 scales of the SF-36 questionnaire, when compared to those without ( $P<0.0005, P<0.001, P<0.0005$, respectively). When compared to subjects diagnosed with GERD only, those with overlapping GERD + FD, GERD + IBS, and GERD + FD + IBS had lower scores on 5, 8, and 6 subscales of the SF-36 questionnaire, when compared with those diagnosed with GERD only $(P<0.001, P<0.0005, P<0.001$, respectively $) .^{52}$

A nationwide study of 100000 individuals within the Danish population used a web-based questionnaire survey. Respondents with GERD-FD or GERD-IBS complexes had significantly higher odds of reporting poor self-rated health (OR, 6.07 vs 3.33) and impaired functional capacity (OR, 6.05 vs 2.88), compared to respondents with GERD alone. The individuals with 3 symptom complexes (GERD, FD, and IBS) were at the highest risk for reporting poor self-rated health $(\mathrm{OR}, 13.57)$ and impaired functional capacity $(\mathrm{OR}, 10.22)$. $^{53}$

One cross-sectional survey study which enrolled 2641 subjects in the United States found that higher GI symptoms to be more bothersome in the cases with overlapping IBS with constipation (IBS-C)-GERD (65.7\%) or IBS-C-GERD-FD (73.5\%) than those with GERD only (28.3\%). The percentage of respondents who sought physician care for GI symptoms in the past 12 months of the study was also highest in the group with overlapping IBSGERD-FD (67.3\%), following by the groups of overlapping GERD-FD (58.9\%) and GERD only (56.6\%). ${ }^{35}$

Table 2 summarizes studies demonstrating the impact of HRQoL of subjects with overlapping GERD and FGIDs.

\section{Treatments for Overlapping Gastroesopha- geal Reflux Disease and Functional Gastro- intestinal Disorders}

The management of GERD and FGIDs include the avoidance of risk factors through both lifestyle and dietary modifications. To the individuals with GERD, acid secretion suppressors are considered the most effective means towards determining adequate symptom relief, while proton pump inhibitors (PPIs) are the most potent agents. ${ }^{54}$ 


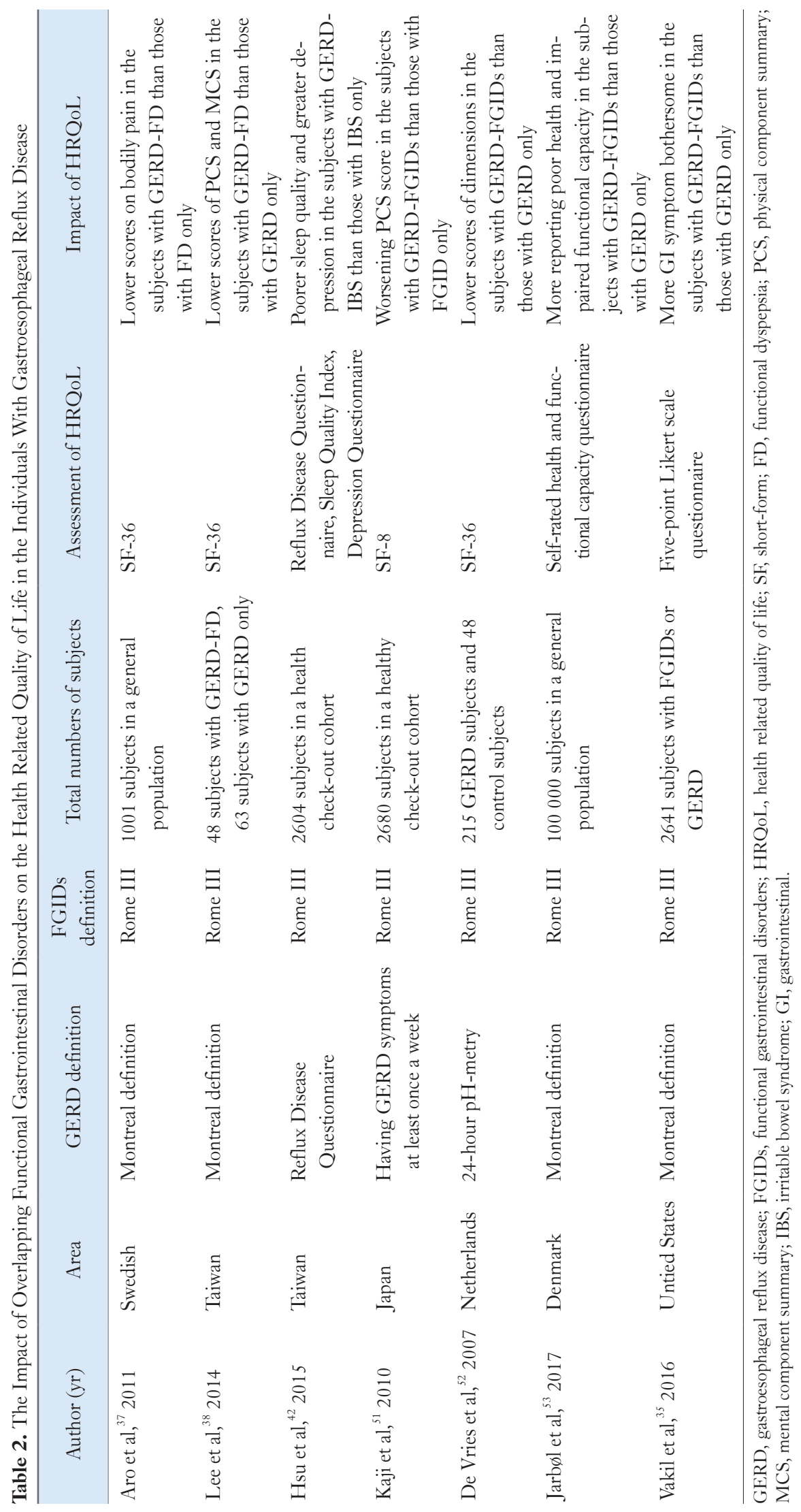


However, according to previous studies, the presence of FGIDs reduced the response to PPIs in GERD patients. ${ }^{55,56}$ Whereas on the contrary, some past reports found the symptoms of FGIDs resolution of patients after PPI therapy. ${ }^{57,58}$ The reason for this may be due to PPIs being associated with alterations in intestinal barrier function, ${ }^{59}$ and subsequently with secondary changes in intestinal microbiota composition, ${ }^{60}$ which could be a determining role in FGIDs pathogenesis.

Considering the sharing pathogenesis of GERD and FGIDs, the medications which are aimed at reducing visceral sensitivity, including tricyclic antidepressant agents, selective serotonin reuptake inhibitors, and serotonin-norepinephrine reuptake inhibitors, may offer therapeutic benefits to individuals with any overlapping syndromes. ${ }^{61}$ Unfortunately, few studies have been performed in the past. Therefore, further investigation regarding effective therapies for both GERD and FGIDs needs to be performed.

Past studies that have discussed the therapeutic efficacy of prokinetics to patients with GERD and FGIDS were few. One small, randomized controlled trial with tegaserod (a 5-hydroxytryptamine 4 agonist), enrolling 25 cases with overlapping GERD and FD (Rome II), were randomized to receive tegaserod or a placebo. However, tegaserod did not achieve overall symptom improvement. ${ }^{62}$ The role of prokinetics to these subjects should need larger studies for confirmation.

\section{Conclusion}

Risk factors involving impaired HRQoL in individuals with GERD include being a younger age, obesity, an increase in reflux symptom frequency, and overlapping FGIDs. The risk factors for subjects experiencing an overlap in FGIDs and GERD involve those who are female, younger age, cigarette smoking, NERD, more GERD symptoms, and psychological performances including anxiety, somatization and more frequent healthcare-seeking behavior. The overlap of GERD and FGIDs is associated with the worsening of both physical and mental health, an increase in bothersome syndromes, an impaired functional capacity, and a greater likelihood to consult physicians. Acid secretion suppressors may offer therapeutic efficacy to some patients with overlapping GERD and FGIDs. Clinical guidelines and regulatory guidance may need to be followed for those patients with overlapping disorders, due to a substantial proportion of patients seeking health care.

\section{Financial support: None.}

\section{Conflicts of interest: None.}

Author contributions: Shou Wu Lee and Chi-Sen Chang conducting the study; Shou Wu Lee collecting and/or interpreting data; and Shou Wu Lee and Chi-Sen Chang drafting the manuscript.

\section{References}

1. Wiklund I. Review of the quality of life and burden of illness in gastroesophageal reflux disease. Dig Dis 2004;22:108-114.

2. Ronkainen J, Aro P, Storskrubb T, et al. Gastro-oesophageal reflux symptoms and health-related quality of life in the adult general population--the Kalixanda study. Aliment Pharmacol Ther 2006;23:1725-1733.

3. Kulig M, Leodolter A, Vieth M, et al. Quality of life in relation to symptoms in patients with gastro-oesophageal reflux disease-- an analysis based on the ProGERD initiative. Aliment Pharmacol Ther 2003;18:767-776.

4. Talley NJ, Weaver AL, Zinsmeister AR. Impact of functional dyspepsia on quality of life. Dig Dis Sci 1995;40:584-589.

5. Mold JW, Reed LE, Davis AB, Allen ML, Decktor DL, Robinson M. Prevalence of gastroesophageal reflux in elderly patients in a primary care setting. Am J Gastroenterol 1991;86:965-970.

6. Lee SW, Chang CM, Chang CS, Kao AW, Chou MC. Comparison of presentation and impact on quality of life of gastroesophageal reflux disease between young and old adults in a Chinese population. World J Gastroenterol 2011;17:4614-4618.

7. El-Serag HB, Johanson JF. Risk factors for the severity of erosive esophagitis in Helicobacter pylori-negative patients with gastroesophageal reflux disease. Scand J Gastroenterol 2002;37:899-904.

8. El-Serag H. The association between obesity and GERD: a review of the epidemiological evidence. Dig Dis Sci 2008;53:2307-2312.

9. Iovino P, Angrisani L, Galloro G, et al. Proximal stomach function in obesity with normal or abnormal oesophageal acid exposure. Neurogastroenterol Motil 18:425-432.

10. Vakil N, van Zanten SV, Kahrilas P, Dent J, Jones R. The Montreal definition and classification of gastroesophageal reflux disease: a global evidence-based consensus. Am J Gastroenterol 2006;101:1900-1920.

11. Dent J, Brun J, Fendrick A, et al. An evidence-based appraisal of reflux disease management--the Genval Workshop Report. Gut 1999;44(suppl 2):S1-S16.

12. Talley NJ, Stanghellini V, Heading RC, Koch KL, Malagelada JR, Tytgat GN. Functional gastroduodenal disorders. Gut 1999;45(suppl 2):II37-II42.

13. Tack J, Talley NJ, Camilleri M, et al. Functional gastroduodenal disorders. Gastroenterology 2006;130:1466-1479.

14. Drossman DA. The functional gastrointestinal disorders and the Rome III process. Gastroenterology 2006;130:1377-1390.

15. Drossman DA, Hasler WL. Rome IV-functional GI disorders: disorders of gut-brain interaction. Gastroenterology 2016;150:1257-1261.

16. Zimmerman J, Shohat V, Tsvang E, Arnon R, Safadi R, Wengrower D. Esophagitis is a major cause of upper gastrointestinal hemorrhage in the elderly. Scand J Gastroenterol 1997;32:906-909.

17. Pilotto A, Franceschi M, Leandro G, Novello R, Di Mario F, Valerio G. 
Long-term clinical outcome of elderly patients with reflux esophagitis: a six-month to three-year follow-up study. Am J Ther 2002;9:295-300.

18. Dekel R, Green C, Quan S, Stephen G, Fass R. The relationship between severity and frequency of symptoms and quality of sleep (QOS) in patients with gastroesophageal reflux disease (GERD). Gastroenterology 2003;124:A414.

19. Lippmann QK, Crockett SD, Dellon ES, Shaheen NJ. Quality of life in GERD and Barrett's esophagus is related to gender and manifestation of disease. Am J Gastroenterol 2009;104:2695-2703.

20. Locke GR 3rd, Talley NJ, Fett SL, Zinsmeister AR, Melton LJ 3rd. Risk factors associated with symptoms of gastroesophageal reflux. Am J Med 106:642-649.

21. Wilson LJ, Ma W, Hirschowitz BI. Association of obesity with hiatal hernia and esophagitis. Am J Gastroenterol 94:2840-2844.

22. Sullivan M, Karlsson J, Sjöström L, et al. Swedish obese subjects (SOS)-an intervention study of obesity. Baseline evaluation of health and psychosocial functioning in the first 1743 subjects examined. Int J Obes Relat Metab Disord 1993;17:503-512.

23. Savarino E, Zentilin P, Savarino V. NERD: an umbrella term including heterogenous subpopulations. Nat Rev Gastroenterol Hepatol 2013;10:371-380.

24. Fennerty MB, Johnson DA. Heartburn severity does not predict disease severity in patients with erosive esophagitis. Med Gen Med 2006;8:6.

25. Kovács Z, Kerékgyártó O. Psychological factors, quality of life, and gastrointestinal symptoms in patients with erosive and non-erosive reflux disorder. Int J Psychiatry Med 2007;37:139-150.

26. Lee SW, Lee TY, Lien HC, Yang SS, Yeh HZ, Chang CS. Characteristics of symptom presentation and risk factors in patients with erosive esophagitis and nonerosive reflux disease. Med Princ Pract 2014;23:460464.

27. Wiklund I, Carlsson J, Vakil N. Gastroesophageal reflux symptoms and well-being in a random sample of the general population of a Swedish community. Am J Gastroenterol 2006;101:18-28.

28. Revicki DA, Zodet MW, Joshua-Gotlib S, Levine D, Crawley JA. Health-related quality of life improves with treatment-related GERD symptom resolution after adjusting for baseline severity. Health Qual Life Outcomes 2003;1:73.

29. Kaplan-Machlis B, Spiegler GE, Revicki DA. Health-related quality of life in primary care patients with gastroesophageal reflux disease. Ann Pharmacother 1999;33:1032-1036.

30. Wahlqvist P, Carlsson J, Stålhammar NO, Wiklund I. Validity of a work productivity and activity impairment questionnaire for patients with symptoms of gastro-esophageal reflux disease (WPAI-GERD)--results from a cross-sectional study. Value Health 2002;5:106-113.

31. Wahlqvist P, Karlsson M, Johnson D, Carlsson J, Bolge SC, Wallander MA. Relationship between symptom load of gastro-oesophageal reflux disease and health-related quality of life, work productivity, resource utilization and concomitant diseases: survey of a US cohort. Aliment Pharmacol Ther 2008;27:960-970.

32. Tack J, Becher A, Mulligan C, Johnson DA. Systematic review: the burden of disruptive gastro-oesophageal reflux disease on health-related quality of life. Aliment Pharmacol Ther 2012;35:1257-1266.
33. Kahrilas PJ, Howden CW, Wernersson B, Denison H, Nuevo J, Gisbert JP. Impact of persistent, frequent regurgitation on quality of life in heartburn responders treated with acid suppression: a multinational primary care study. Aliment Pharmacol Ther 37:1005-1010.

34. Locke GR 3rd, Talley NJ, Fett SL, Zinsmeister AR, Melton LJ 3rd. Prevalence and clinical spectrum of gastroesophageal reflux: a population-based study in Olmsted County, Minnesota. Gastroenterology 1997;112:1448-1456.

35. Vakil N, Stelwagon M, Shea EP, Miller S. Symptom burden and consulting behavior in patients with overlapping functional disorders in the US population. United European Gastroenterol J 2016;4:413-422

36. Guillemot F, Ducrotté P, Bueno L. Prevalence of functional gastrointestinal disorders in a population of subjects consulting for gastroesophageal reflux disease in general practice. Gastroenterol Clin Biol 2005;29:243246.

37. Aro P, Talley NJ, Agréus L, et al. Functional dyspepsia impairs quality of life in the adult population. Aliment Pharmacol Ther 2011;33:12151224.

38. Lee SW, Lee TY, Lien HC, Yeh HZ, Chang CS, Ko CW. The risk factors and quality of life in patients with overlapping functional dyspepsia or peptic ulcer disease with gastroesophageal reflux disease. Gut Liver 2014;8:160-164.

39. de Bortoli N, Martinucci I, Bellini M, et al. Overlap of functional heartburn and gastroesophageal reflux disease with irritable bowel syndrome. World J Gastroenterol 2013;19:5787-5797.

40. Lovell RM, Ford AC. Prevalence of gastro-esophageal reflux-type symptoms in individuals with irritable bowel syndrome in the community: a meta-analysis. Am J Gastroenterol 2012;107:1793-1801.

41. Rasmussen S, Jensen TH, Henriksen SL, et al. Overlap of symptoms of gastroesophageal reflux disease, dyspepsia and irritable bowel syndrome in the general population. Scand J Gastroenterol 2015;50:162-169.

42. Hsu CS, Liu TT, Wen SH, et al. Clinical, metabolic, and psychological characteristics in patients with gastroesophageal reflux disease overlap with irritable bowel syndrome. Eur J Gastroenterol Hepatol 2015;27:516522.

43. Hsu CS, Wen SH, Hung JS, et al. Overlap of dyspepsia in patients with gastroesophageal reflux disease: impact of clinical, metabolic, and psychosocial characteristics. Dig Dis Sci 2017;62:994-1001.

44. Chang L. Review article: epidemiology and quality of life in functional gastrointestinal disorders. Aliment Pharmacol Ther 2004;20(suppl 7):3139.

45. Mori H, Suzuki H, Matsuzaki J, et al. Gender difference of gastric emptying in healthy volunteers and patients with functional dyspepsia. Digestion 2017;95:72-78.

46. Fujiwara Y, Kubo M, Kohata Y, et al. Cigarette smoking and its association with overlapping gastroesophageal reflux disease, functional dyspepsia, or irritable bowel syndrome. Intern Med 2011;50:2443-2447.

47. Noh YW, Jung HK, Kim SE, Jung SA. Overlap of erosive and nonerosive reflux diseases with functional gastrointestinal disorders according to Rome III criteria. J Neurogastroenterol Motil 2010;16:148-156.

48. Nam SY, Ryu KH, Park BJ. Irritable bowel syndrome is associated with gastroesophageal reflux symptom but not erosive esophagitis. J Neuro- 
gastroenterol Motil 2013;19:521-531.

49. Jung HK, Halder S, McNally M, et al. Overlap of gastro-oesophageal reflux disease and irritable bowel syndrome: prevalence and risk factors in the general population. Aliment Pharmacol Ther 2007;26:453-461.

50. Lee SY, Lee KJ, Kim SJ, Cho SW. Prevalence and risk factors for overlaps between gastroesophageal reflux disease, dyspepsia, and irritable bowel syndrome: a population-based study. Digestion 2009;79:196-201.

51. Kaji M, Fujiwara Y, Shiba M, et al. Prevalence of overlaps between GERD, FD and IBS and impact on health-related quality of life. J Gastroenterol Hepatol 2010;25:1151-1156.

52. De Vries DR, Van Herwaarden MA, Baron A, Smout AJ, Samsom M. Concomitant functional dyspepsia and irritable bowel syndrome decrease health-related quality of life in gastroesophageal reflux disease. Scand J Gastroenterol 42:951-956.

53. Jarbøl DE, Rasmussen S, Balasubramaniam K, Elnegaard S, Haastrup PF. Self-rated health and functional capacity in individuals reporting overlapping symptoms of gastroesophageal reflux disease, functional dyspepsia and irritable bowel syndrome - a population based study. BMC Gastroenterol 2017;17:65.

54. Katz PO, Gerson LB, Vela MF. Guidelines for the diagnosis and management of gastroesophageal reflux disease. Am J Gastroenterol 2013;108:308-328.

55. Garros A, Mion F, Marjoux S, Damon H, Roman S. Factors associated with nonresponse to proton pump inhibitors therapy in patients referred for esophageal pH-impedance monitoring. Dis Esophagus 29:787-793.
56. Mönnikes H, Heading RC, Schmitt H, Doerfler H. Influence of irritable bowel syndrome on treatment outcome in gastroesophageal reflux disease. World J Gastroenterol 2011;17:3235-3241.

57. Kinoshita Y, Miwa H, Sanada K, Miyata K, Haruma K. Clinical characteristics and effectiveness of lansoprazole in Japanese patients with gastroesophageal reflux disease and dyspepsia. J Gastroenterol 2014;49:628637.

58. Kountouras J, Chatzopoulos D, Zavos C, Boura P, Venizelos J, Kalis A. Efficacy of trimebutine therapy in patients with gastroesophageal reflux disease and irritable bowel syndrome. Hepatogastroenterology 2002;49:193-197.

59. Mullin JM, Valenzano MC, Whitby M, et al. Esomeprazole induces upper gastrointestinal tract transmucosal permeability increase. Aliment Pharmacol Ther 2008;28:1317-1325.

60. Lombardo L, Foti M, Ruggia O, Chiecchio A. Increased incidence of small intestinal bacterial overgrowth during proton pump inhibitor therapy. Clin Gastroenterol Hepatol 2010;8:504-508.

61. de Bortoli N, Tolone S, Frazzoni M, et al. Gastroesophageal reflux disease, functional dyspepsia and irritable bowel syndrome: common overlapping gastrointestinal disorders. Ann Gastroenterol 2018;31:639-648.

62. Miner PB Jr, Rodriguez-Stanley S, Proskin HM, Kianifard F, Bottoli I. Tegaserod in patients with mechanical sensitivity and overlapping symptoms of functional heartburn and functional dyspepsia. Curr Med Res Opin 2008;24:2159-2172. 